\title{
The Road to Parenthood: Income and First Births in Sweden
}

\author{
ERNESTO G. SILVA \\ Lund University, Sweden
}

\begin{abstract}
This paper considers the effect of income on the risk of having first births in Sweden from 1969 to 2009. Variations by gender are given particular attention. The study follows men and women from the moment they turn 18 until they enter parenthood and it is based on register-based data covering the entire population of Sweden. Complementary log-log models show that there is a positive association between income and the risk of childbearing. The association gets stronger over time and the differences between men and women diminish. Gender differences appear when the income effect is related to the demand for work in the economy. An income above the median does not increase the risk of childbearing for women when the demand for work is relatively high.
\end{abstract}

Keywords: Entry into parenthood, income, fertility, family policies, Nordic fertility, Sweden

\section{Introduction}

Entry into parenthood is perhaps the most relevant event in the transition to adulthood considering its long lasting impact on the lifestyle, career prospects, and financial status of the parents. Parenthood commonly follows other transitional steps like entering the labour market, leaving the parental home, and forming a union.

The focus of this paper is on the relationship between income and the risk of having the first child. Income is obviously connected with entry into the labour market. If income somewhat reflects productivity, then a higher income not only is related to higher consumption possibilities, but also with a more solid position in the labour market or at least a better leverage when negotiating labour conditions or looking for a new job. All factors that matter for raising children. Additionally, being in a good position to afford children may work as an asset in the marriage market.

This paper covers four decades (1969-2009) in which family policies consolidated giving parents a better set of options, from parental leave to subsidized childcare services, in order to make family life and work more compatible. While conditions to reduce the opportunity costs improved, other aspects deteriorated. Economic security is probably higher for the average Swede compared with most other developed countries (EspingAndersen 1990; Olsson 1993). However, the rise in unemployment after the crisis in 
the early 1990s and structural changes in the labour market that partially reversed the previous compression of the wage structure have adversely affected the position of those at the bottom of the income distribution (Björklund and Freeman 1994; Lindbeck 1997; Johansson 2006; Waldenström 2009; Bengtsson, Holmlund and Waldenström 2012; Schön 2012). Being at the lower end of the income distribution throughout the 1990s was relatively worse than being in a similar situation 20 years before. At the same time, those at the upper end of the income distribution are likely to have seen their wages increase and their taxes reduced.

The result is two forces pushing in the same direction. Insecurity at the bottom and more options to reduce the opportunity costs of children at the top. These two factors basically explain why I expect to find a positive association between income and entry into parenthood, and why I expect the positive association to get stronger over time. Changes in family patterns and policies that relate parental benefits with labour experience explain why I also expect the association to become more similar for men and women during this period.

The study will be conducted with register-based data covering the whole native born population living in Sweden from 1969 to 2009. The extent of the coverage, the quality of the income data -taken from administrative registers-, represents an important contribution to the existing literature. The long time span is another important aspect since there are not many studies on how the relationship between economic factors and fertility has evolved over time (Kravdal and Rindfuss 2008).

\section{Previous Research}

Previous studies suggest that younger generations of Swedes want to have education, employment and some savings before becoming parents, as they regard parenthood as a demanding career (Hoem 1992; Santow and Bracher 2001). Postponement of parenthood is a common trend across developed countries and can be regarded as one of the most relevant individual adjustments to changing economic incentives, such as prolonged schooling or the need to have an established position in the labour market before childbearing. Whether or not the timing of the first child has a sizeble economic impact is debated among researchers (Happel, Hill and Low 1984; Miller 2011).

Regardless of the impact on future earnings, it is clear that postponement is not unrelated to human capital investment as average age at first birth increases with education. Most studies tend to show that school enrolment has a strong negative impact on childbearing, especially for women (Liefbroer and Corijn 1999; Andersson 2000; Hoem 2000; Lappegård and Ronsen 2005; Dribe and Stanfors 2009; Tesching 2012). Thalberg (2011) has shown that part of the negative impact of enrolment on childbearing is due to the lower income earned by students. Previous research has also established that the impact of education on the risk of having the first child varies with age. Lower education increases the risk of having a child for women in their early twenties, but 
not for women in their thirties (Tesching 2012). For this reason, age is controlled for in every model used in this study.

Most studies on fertility focus on women and how their role in the labour market or their educational attainment affects their fertility. The association between fertility and female employment is debated across developed countries (Bernhardt 1993; Brewster and Rindfuss 2000; Ahn and Mira 2002; Kögel 2004; Matysiak and Vignoli 2008), but most studies based on Swedish data tend to confirm the Nordic Fertility Regime. Swedish women tend to establish themselves in the labour market before motherhood (Hoem 2000; Andersson 2000; Dribe and Stanfors 2009). The same pattern was observed among immigrant women living in Sweden (Andersson and Scott 2007). Santow and Bracher (2001) show that having two years of full time work increases the risk of motherhood for Swedish women. A similar time span is observed in Norway (Kravdal 1994), even though parental leave only requires six months of previous working experience. This is in contrast to studies done in not so distant countries. Liefbroer and Corijn (1999) found that having no job delays fatherhood for Flemish men, has no impact for Dutch men, but facilitates motherhood for Flemish and Dutch women. These results support the notion that the social policies applied in the Nordic countries may have influenced fertility trends.

The rationale for the particular focus on women when it comes to the economic aspects of fertility is related to the differential impact that fertility has for men and women. There is near consensus in previous research showing that women carry the main burden of the opportunity costs of children (Joshi 1990; Budig and England 2001; Breusch and Gray 2004). Despite this, women do not tend to avoid the transition to parenthood altogether and they are less likely than men to remain childless at the end of their reproductive age. However, highly educated women are the exception (Kravdal and Rindfuss 2008; Boschini et al. 2011). This positive association between education and childlessness among women, contrasting with the negative association observed in men (Lappegård, Ronsen and Skrede 2011), can be interpreted as signaling that well-educated women are more career oriented and therefore more likely to skip motherhood but also that the opportunity costs of children are still too high for women with high potential income.

There are some interesting studies on the role of policies alleviating opportunity costs and the relationship between income and fertility. Berninger (2013) compares how income affects the risk of having the first child for women in Finland and Denmark in the 1990s. She found that high income increases the risk of a woman entering motherhood in Denmark but not in Finland and concluded that that was the result of policies more oriented to reduce opportunity costs. The author suggests that the introduction of the homecare allowance in Finland may have stimulated the fertility of low income women and therefore reduced the significance of the income coefficient. Since Sweden does not have any specific homecare allowance, policies are closer to that of Denmark than to Finland, I would expect to find a positive association between income and fertility for 
Swedish women too (for a detailed view on Swedish family policies see Meyer 2007).

From a macroeconomic perspective, the counter cyclical fertility predicted by earlier studies (Butz and Ward 1979) was not confirmed by subsequent studies (see Sobotka, Skirbekk and Philipov 2011). Recessions tend to increase the gap between income aspirations and actual income, which is a factor that delays family formation (Lutz, Skirbekk and Testa 2006). Pro-cyclical fertility has been documented in Sweden beginning in the 1970s (Andersson 2000; Stanfors 2003). There is no reason to expect a different result in this study. Regardless, the correlation between entry into parenthood and economic cycles is tested as background information.

\section{Theoretical Framework}

From a New Home Economics perspective, children can be seen as commodities. Commodities are what households produce, combining time and market goods in order to maximize utility. Such conceptualization is useful to understand the cost of children because such costs include both the market price of the goods required for rearing children and the forgone earnings for the time spent in childrearing chores instead of in paid work (Gronau 1977; Becker 1991). The role of income in the transition to parenthood is double edged: it facilitates the acquisition of market goods (income effect), but it also increases the value of time (substitution effect). The relationship of income and fertility will depend on whether the income effect or the substitution effect prevails.

Traditional views on the family were based on the assumption of a household division in which men have a relative advantage for market work, while women have an advantage in household labour (Becker 1991). If the man is going to be the breadwinner and not the caregiver after a child is born, the more he earns the more affordable the child will be. Also, if men are expected to be providers, then a higher income should make them more attractive in the marriage market. Both elements reinforce each other therefore, ambiguity is not expected for men: a higher income should increase the risk of fatherhood (Lappegård, Ronsen and Skrede 2011). On the other hand, if the woman is going to take most of the childrearing responsibility, then a higher income would increase her ability to purchase market goods but also the cost of the time she will spend out of the labour market. Under such a scenario, the impact of income on women becoming mothers is ambiguous and the extent of the incompatibility between work and family life will play an important role on whether or not women with high income decide to have children (Berninger 2013).

The pre-eminence of the male breadwinner family has been phased out by the rising participation of women in the labour force and the increasing number of mothers returning to work after having children (Stanfors 2003; Matysiak and Vignoli 2008). Initially, increased female attachment to the labour force was accompanied by decreased fertility, as the theory predicted (Butz and Ward 1979). However, another change was on the way. As dual earner families became the norm, other social and political changes softened the 
incompatibility between work and family and in doing so altered the economic calculus regarding childbearing (Rindfuss and Brewster 1996; Kögel 2004; Ronsen 2004; Vikat 2004; Björklund 2006; Neyer and Andersson 2008).

Generally speaking, the adjustment to the changing context can be tracked at different levels: postponement of parenthood at the individual level; changing attitudes towards working mothers and the use of childcare facilities at the social level (Hultåker 1982); and the provision of accessible childcare and more generous parental leave schemes at the political level (Castles 2003). These changes are historical processes whose impact on the relationship between income and fertility is more likely to appear as an incremental transformation over time rather than as an abrupt turnover following a particular policy (Ellingsaeter 2009). If the opportunity costs can be characterized by the direct loss of the forgone income plus the loss in human capital for the time spent out of the labour market, a proper response to reduce opportunity costs should confront both issues, combining a wage replacement policy during the time of leave with childcare options that facilitates a rapid return to work (Berninger 2013). The alleviation of opportunity costs may induce more high-income women to enter motherhood as the result of a combination of different policies and social perceptions (e.g., participation of fathers in childcare and public acceptance of external childcare as a normal option for raising children).

Subsidized childcare in Sweden can be tracked back to 1943 but it was in the 1970s when its expansion really became an explicit policy goal (Van Lacker and Ghysels 2012). Nevertheless, it took until the 1990s to reach the point in which the majority of children became users of public day care (Stanfors 2003; Andersson, Duvander, and Hank 2004).

Since 1974 mothers and fathers are allowed to take time away from work for childcare duties, during which time their previous position in the labour markets is guaranteed. Initially they were able to share six months of paid leave at 90 percent replacement of previous earnings, with a cap for higher earnings and a guaranteed minimum level. The number of days was gradually expanded until it reached 16 months in 2002, while the replacement level oscillated between 75 and 80 percent (see Meyer 2007). Parental leave can be taken over a continuous period, piecemeal or part-time before the child turns eight years old.

Such models make it convenient, even for women who plan to stay at home after childbearing, to have a good salary before motherhood. Despite the explicit policy goal of promoting gender equality -and the increasing incentives to share parental leave equally- women still take far more time off from work after a child is born and they are far more likely to take half time jobs when they return to the labour market (Sundström and Duvander 2002; Stanfors 2003; Duvander, Lappegård, and Anderssson 2010).

The fertility behavior of women is expected to experience greater changes over time than that of men, however, the magnitude of the change for women and to what extent men were affected is difficult to predict. On one hand, women are still expected to pay higher opportunity costs while men continue to be the main breadwinners in 
most cases. Income prior to parenthood may be important for men but not as much for women. On the other hand, considering the prospect of union dissolution and/or the will of economic independence, income prior to the transition may be as important -if not more- for women (Jalovaara and Miettinen 2013). Men staying in the labour market after parenthood will retain the opportunity to progress in their careers, while women staying at home will be frozen in their previous position until they return to work. Women that enter motherhood from a low position in the labour market and then spend several years either in parental leave or in half-time work may have more difficulties improving their earnings afterwards.

So far, the analysis has centered on opportunity costs and how policies and social changes have altered the economic calculus about childbearing. In order to have a more comprehensive perspective on the issue, the role of aspirations and the ability to satisfy them should be considered as well (Easterlin 1976; Macunovich 1997). For the purpose of this study, the concept of aspirations will be defined in broad terms so it can cover personal consumption and child quality.

If younger cohorts have increasing expectations about living standards either for themselves or for their children, then parenthood will become more selective in terms of income (Santow and Bracher 2001; Lappegård, Ronsen and Skrede 2011). Additionally, there was a relative decline in economic security, particularly for the cohorts that entered adulthood after 1990. Sweden is still a prosperous country with a generous safety net, but the years of full employment are gone and income inequality has been on the rise (Lindbeck 1997; Schön 2012). People at the lower end of the income distribution after the 1990s crisis are likely to be relatively worse off than those at a similar position in the income distribution of the 1970s.

Aspirations are an unobservable characteristic that cannot be captured by registers. The link between aspirations and fertility will be tested indirectly using the interactions between income and macroeconomic context and between income and educational level.

The rationale for using a macroeconomic context is that aspirations will be harder to fulfill during harsh times, so entry into parenthood would be more selective on income when the economic context is worse. Economic recessions are associated with lower rates of union formation and increased economic uncertainty, two factors with a negative impact on fertility (Sobotka, Skirbekk and Philipov 2011). Many authors have linked low fertility in Eastern and Southern Europe with the difficult circumstances faced by young adults, particularly the difficulties to enter the labour market (Kohler, Billari and Ortega 2002; Billari and Kohler 2004). Sweden is clearly not among the cases of lowest fertility in Europe; however, it is reasonable to think that when economic conditions are worse, and the demand for workers in the labour market is low, the Swedes face similar incentives to postpone fertility. The call to postpone fertility will have a greater impact on those who have not yet attained a relatively solid position in the labour market and therefore the association between income and entry into parenthood will get stronger when the labour market contracts. 


\section{Hypotheses}

The first hypothesis deals with a pattern that has already been established by previous research, nevertheless, I think it is necessary to test it again in this particular setting.

Hypothesis 1 (Positive Income Effect): Considering the incentives to have a foothold in the labour market before parenthood, I expect fertility to be pro-cyclical at the macro level, and a positive association between income and the risk of childbearing at the micro level, for both men and women.

The next hypothesis complements the former by adding the historical factor. Social policies facilitating the combination of work and family have evolved over time, economic security, as well, receded. Both factors should affect how the association between income and parenthood behaved over the study period.

Hypothesis 2 (Consolidation): The positive association between income and entry into parenthood should get stronger over time for both men and women.

Earlier in this paper it was predicted that changes over time (Hypothesis 2) should be greater for women; however, whether or not income would become even more important for women than for men remains unclear from a theoretical perspective. The gender aspect of the association between income and parenthood is thus presented as two alternative hypotheses.

Hypothesis 3 (Male Breadwinner Effect): Since men are still more likely to be the breadwinner after the child is born, it is more important for them to have a higher income before parenthood.

Hypothesis 4 (Risk Reduction and/or Independence): Women are more likely to take time away from a job after childbearing, thus, it could be even more important for them to have a foothold in the labour market before parenthood in order to retain economic independence and to cope with the eventuality of union dissolution -or a negative shock to the partner's income-.

Considering the trend towards greater promotion of gender equality, the expansion of family policies, and the increasing prevalence of less traditional partnership patterns, there could be a historical trend in the relative importance of Hypotheses 3 and 4 (with Hypothesis 3 gaining more relevance in relative terms as we go back in time).

Finally, the impact of individual income on the risk of having the first child should also be tampered by individual aspirations.

Hypothesis 5 (Harsh Context Effect): Aspirations are harder to fulfill in a bad economic context. The transition to parenthood should be more selective on income when demand for work is low. 


\section{Data and Methods}

This study is done with register-based information, maintained by Statistics Sweden, covering all individuals in the birth cohorts from 1942 to 1989 who resided in Sweden after 1969. Registers include data on place of residence, income, and educational level, as well as demographic events (births, migration, and changes in civil status). Individuals are followed from the time they turn 18 years of age -except for those who were born before 1950, in which case they are followed from 1969 onwards, provided they had no children before that date- until they enter parenthood, turn 50 years of age, or the end of the study period in 2009. Observations cover a total of 2,453,701 men and $2,221,940$ women.

Registers only provide information about partners if they are married. Cohabitation is only registered after the couple has a common child, therefore it cannot be used to study entry into parenthood. Considering that marriage is no longer a social requisite for cohabitation, and that more than half of the children are now born out of wedlock, taking only those who marry before parenthood would give an unrepresentative sample of the Swedish population. This is obviously a problem in the sense that knowing whether or not the people at risk of entering parenthood are in a partnership would provide important information for this study. Not only because partnership itself is an important risk factor, but also because partner information may add very relevant factors for consideration such as the income of the partner and how it interacts with personal income.

The only way to perform a study on entry into parenthood using registers is to forgo the couple and embrace an individual perspective. There are some caveats in this strategy but the same loss of centrality of the institution of marriage that made it more difficult to analyze entry into parenthood from the perspective of couples, also made it more relevant to consider the impact of individual characteristics, considering the risk of union dissolution and the increased regard for economic independence in contemporary Sweden.

\section{Empirical Models}

Empirical models are based on duration until parenthood. However, all variables are presented in discrete-time form, meaning that we do not know precisely the point in which the event happens but just the year (the data is interval-censored). A suitable technique for discrete-time analysis when the data is generated by a continuous timeprocess -such as delivering a baby- is the complementary log-log hazard model (see Andress et al. 2013).

The main independent variable of interest is income, which is presented in terms of deciles. The fifth decile -the one falling immediately below the median- was chosen as the reference category for the presentation of results.

Income figures were constructed using data provided by Statistics Sweden on labour related income before taxation. This concept includes wages for employees and selfemployed, as well as other benefits related to labour, such as unemployment benefits, 
parental leave, payment from sickness insurance, and pensions. People living from disability pensions or entirely by income from capital are thus excluded from the study. Income from those sources is not related to the time a persons dedicates to work and therefore such income is not affected by childbearing in the same way.

Deciles are calculated on an annual basis: individuals are given a decile according to their annual income in a given year in relation to other individuals included in the sample. These deciles are calculated within the total population at risk of having the first child. Being at decile 10, for example, means that an individual is among the top ten percent of earners, during the given year, among the other childless individuals, male or female, that are included in the study.

Women tend to have their children younger and they usually enter parenthood with lower earnings than do men. They contribute with fewer observation at the top deciles. I chose this specification because I wanted the deciles to refer to a similar income level for both genders.

There are three variations of the income deciles. In the standard model, only income from the previous year (yt-1) is considered. There are also two alternative models in which deciles are calculated based on what individuals have made in the last two $\left(\mathrm{y}_{\mathrm{t}-1}+\mathrm{y}_{\mathrm{t}-2}\right)$ or three $\left(\mathrm{y}_{\mathrm{t}-1}+\mathrm{y}_{\mathrm{t}-2}+\mathrm{y}_{\mathrm{t}-3}\right)$ years respectively.

Persons who earn low salaries but receive a large amount of income from capital, such as young people who have inherited wealth, may be miscategorized as they will be included in lower deciles whilst having extra resources at their disposal. Nevertheless, I would not expect this to be a major problem since the latter is usually not a common case.

Educational level is used as a control. The education variable is based on the standard classification of Svensk Utbildningsnomenklatur (SUN) as provided by Statistics Sweden and it refers to the highest degree obtained. However, the quality of the data is not even across the full spectrum of the study. After 1990, register data on educational level is given on an annual basis. Before 1990, educational level must be inferred from census data and information on the year of the last graduation. To minimize the risk of mislabeling, education is measure in three basic levels: compulsory (9 to 10 years of schooling or less), secondary (which also includes postsecondary programs that last less than three years), and tertiary (postsecondary degrees that last three years or more). If no other information is available, individuals are automatically placed in the lower educational category. Information given by the 1970 census is the first element considered and this information replaces the default position. The next step is to extend the educational level attained in 1990 back to the graduation year. Those who have attained the higher educational level are assumed to have acquired secondary level educations five years before graduation.

The other problem is the absence of data of actual enrolment in education. Student status can be inferred from two different sources. One is the money received, as all adults in higher education in Sweden are entitled to receive study grants and loans (Thalberg 2011; Tesching 2012). Unfortunately, the series for this concept are also incomplete. 
Therefore, the chosen measure was to look at changes in the educational level attained and assume that the individual was enrolled from the time he or she enters the study at age 18 until the last graduation occurrence. What this dummy variable properly measures is whether or not an individual has finished his or her studies. It is clearly an imperfect measure, but it should work as an approximation since individuals that have not finished their education are more likely to be enrolled at any point of the study. The variable provides a proxy for the likelihood of being enrolled in education.

Economic activity is controlled for in the form of the demand for work -the number of vacancies generated throughout the year (see Stanfors 2003, for a discussion on vacancies as a business cycle indicator). The variable is presented in ordinal form: years are classified in quintiles according to the number of vacancies generated. The top quintile represents higher demand for work and the opposite is true for the lower quintile. Vacancies tend to mirror the evolution of unemployment, but the figures are more stable over the period of this study. For example, the years 1992 to 1997 exhibit high unemployment and a low number of vacancies, so these years clearly fall into the lower quintile. However, in 2007 unemployment was 6.1 which is not particular bad after the 1990s crisis, but still higher than pre-crisis levels. Using vacancies, 2007 falls into the top quintile.

Age is controlled by a set of dummy variables for every specific age. Birth cohorts are also controlled for (in combination with age, which also provides a period control).

The models were run separately for men and women to allow different patterns of association between the outcome and the independent variables. All covariates are presented with one year lag. Results are presented as exponentiated coefficients and should be interpreted as how changes in the given variables relate to the relative risk of having a child the following calendar year.

Additional models were ran to capture the net effect of income in different time periods, as well as across vacancies quintiles. Net effects were obtained by multiplying the coefficient on income deciles and interactions terms between income deciles and timeperiods (income* ${ }^{*}$ period) and income deciles and vacancies quintiles (income*vacancies). The same controls were included as covariates (when time periods were included, cohort was not to avoid collinearity).

\section{Descriptive Statistics}

Since men tend to enter parenthood older than do women, it is not strange that they provide the majority of the observations in this study as each person contributes with one observation per year (Table 1). The number of events is rather stable across the study period. As expected, the median age at childbearing increases throughout the periods and the difference between men and women is usually two years. 
Table 1: Distribution of observations and events by period

\begin{tabular}{cccccccc}
\hline \hline & & \multicolumn{2}{c}{ Observations (x1000) } & \multicolumn{2}{c}{ Evetns: Births (x1000) } & \multicolumn{2}{c}{ Median Age at Event } \\
& & Men & Women & Men & Women & Men & Women \\
\hline Period & $\mathbf{1 9 6 9 - 7 9}$ & 6,163 & 4,485 & 373 & 403 & 26 & 24 \\
& $\mathbf{1 9 8 0 - 8 9}$ & 7,555 & 5,556 & 348 & 356 & 28 & 25 \\
& $\mathbf{1 9 9 0 - 9 9}$ & 8,631 & 6,381 & 356 & 362 & 29 & 27 \\
& $\mathbf{2 0 0 0 - 0 9}$ & 8,632 & 6,503 & 354 & 354 & 31 & 29 \\
Total & & $\mathbf{3 0 , 9 8 1}$ & $\mathbf{2 2 , 9 2 5}$ & $\mathbf{1 , 4 3 0}$ & $\mathbf{1 , 4 7 6}$ & & \\
\hline
\end{tabular}

Notes: Own calculation based on data from SCB (Statistics Sweden). Each individual contributes with one observation per year until the event happens.

Table 2 shows the evolution of the income distribution for the population under study. Keep in mind that the table refers to the income inequality only within the sample and cannot be extrapolated to the general population. In the table we can see how the mean income of the total sample grew over the decades. The table also shows the ratios of decile 10 to decile 1 and decile 9 to decile 2 . The later measure is perhaps better than the former since the upper and lower deciles capture extreme cases. Especially, the lowest decile is mostly composed of students and people with little to no income at all. As education expands, more individuals in the sample receive low incomes. Meanwhile, the postponement of parenthood means that individuals remain in the sample longer and older people tend to contribute with bigger salaries.

Table 2: Income distribution within the sampled individuals

\begin{tabular}{|c|c|c|c|c|c|}
\hline & & 1969-79 & 1980-89 & 1990-99 & 2000-09 \\
\hline \multirow{10}{*}{ 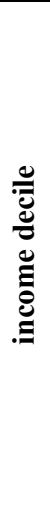 } & decile 1 & 5.6 & 7.4 & 2.2 & 0.9 \\
\hline & decile 2 & 28.8 & 25.5 & 14.1 & 14.0 \\
\hline & decile 3 & 43.5 & 45.9 & 32.9 & 34.9 \\
\hline & decile 4 & 60.2 & 65.1 & 57.7 & 60.9 \\
\hline & decile 5 & 75.5 & 82.2 & 81.9 & 91.9 \\
\hline & decile 6 & 87.9 & 94.7 & 99.8 & 119.0 \\
\hline & decile 7 & 98.7 & 104.7 & 113.8 & 139.9 \\
\hline & decile 8 & 109.8 & 114.9 & 128.1 & 159.8 \\
\hline & decile 9 & 123.4 & 128.6 & 147.2 & 186.4 \\
\hline & decile 10 & 161.5 & 174.2 & 209.7 & 273.9 \\
\hline \multicolumn{2}{|c|}{ Mean Income } & 79.0 & 84.2 & 88.6 & 107.8 \\
\hline \multicolumn{2}{|c|}{ Ratio 10 to 1} & 28.6 & 23.6 & 96.1 & 300.3 \\
\hline \multicolumn{2}{|c|}{ Ratio 9 to 2} & 4.3 & 5.0 & 10.4 & 13.3 \\
\hline
\end{tabular}

Notes: Every cell represents the average income received by a person that belonged to any of the income deciles thourghout the respective decades. Income is presented in tens of thousands of constant kronor (1949). 
Table 3 not only represents the fact that educational attainment increased for the whole population in Sweden, particularly for women, but also the fact that postponement of parenthood implies that more people remain childless until they finish their education, this is especially true for women (see next section).

Table 3: Distribution of educational attainment (\%) for men and women in different periods

\begin{tabular}{lrcccc}
\hline \hline & & & & & \\
& & $1969-79$ & $1980-89$ & $1990-99$ & $2000-09$ \\
\hline men & compulsory & 51.6 & 41.1 & 21.1 & 16.8 \\
& secondary & 44.2 & 53.3 & 71.6 & 68.5 \\
& tertiary & 4.2 & 5.6 & 7.3 & 14.8 \\
\hline \multirow{2}{*}{ women } & compulsory & 49.8 & 40.6 & 16.9 & 13.5 \\
& secondary & 45.6 & 53.3 & 73.8 & 64.5 \\
& tertiary & 4.6 & 6.1 & 9.3 & 22.1 \\
\hline
\end{tabular}

Notes: Educational categories refer to the highest degree obtained and are based on the standard classification of Svensk Utbildningsnomenklatur (SUN) provided by Statistics Sweden. The table shows the percentage of observations corresponding to each category.

\section{Results}

As we can see in Table 4, there is an almost linear relationship in which the lower the income the lower the risk of having the first child. The positive association between income and the risk of childbearing is consistent regardless of whether income is taken with one year lag (column I) or as a combination of the past two or three years (columns II and III) respectively. To the point that the coefficients are quite similar across all three models. 
Table 4: Complementary Log-log Models

\begin{tabular}{|c|c|c|c|c|c|c|c|}
\hline & & \multicolumn{3}{|c|}{ Men } & \multicolumn{3}{|c|}{ Women } \\
\hline & & $\mathbf{I}$ & II & III & $\mathbf{I}$ & II & III \\
\hline \multirow{10}{*}{ 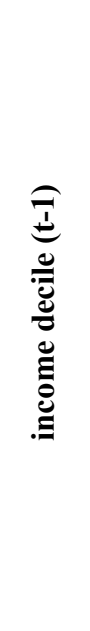 } & decile 1 & 0.54 & 0.49 & 0.47 & 0.42 & 0.42 & 0.43 \\
\hline & decile 2 & 0.58 & 0.60 & 0.61 & 0.42 & 0.49 & 0.53 \\
\hline & decile 3 & 0.67 & 0.72 & 0.74 & 0.54 & 0.62 & 0.68 \\
\hline & decile 4 & 0.83 & 0.87 & 0.88 & 0.77 & 0.80 & 0.84 \\
\hline & decile 5 & 1.00 & 1.00 & 1.00 & 1.00 & 1.00 & 1.00 \\
\hline & decile 6 & 1.14 & 1.11 & 1.10 & 1.15 & 1.16 & 1.15 \\
\hline & decile 7 & 1.30 & 1.27 & 1.24 & 1.17 & 1.22 & 1.22 \\
\hline & decile 8 & 1.41 & 1.41 & 1.38 & 1.13 & 1.19 & 1.21 \\
\hline & decile 9 & 1.51 & 1.52 & 1.49 & 1.11 & 1.18 & 1.21 \\
\hline & decile 10 & 1.74 & 1.75 & & 1.22 & 1.30 & 1.34 \\
\hline \multirow{3}{*}{ 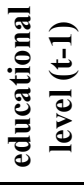 } & compulsory & 0.98 & 0.98 & 0.97 & 1.05 & 1.04 & 1.03 \\
\hline & secondary & 1.00 & 1.00 & 1.00 & 1.00 & 1.00 & 1.00 \\
\hline & terciary & 1.15 & 1.19 & 1.23 & 1.23 & 1.26 & 1.30 \\
\hline \multicolumn{2}{|c|}{ enrolment (t-1) } & 0.93 & 0.93 & 0.92 & 0.68 & 0.67 & 0.66 \\
\hline \multirow{5}{*}{ 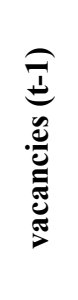 } & quintile 1 & 0.94 & 0.94 & 0.94 & 0.92 & 0.92 & 0.92 \\
\hline & quintile 2 & 1.02 & 1.02 & 1.02 & 1.01 & 1.02 & 1.02 \\
\hline & quintile 3 & 1.00 & 1.00 & 1.00 & 1.00 & 1.00 & 1.00 \\
\hline & quintile 4 & 1.19 & 1.19 & 1.19 & 1.20 & 1.20 & 1.21 \\
\hline & quintile 5 & 1.41 & 1.41 & 1.41 & 1.40 & 1.41 & 1.42 \\
\hline
\end{tabular}

Notes: Results are presented as exponentiated coefficients. In the first column, deciles are based on last year income. Columns II and III include income deciles that take into account income from the last two and three years respectively. All other explanatory variables are lagged one year. Enrolment is defined as $0=$ not enrolled, $1=$ enrolled. Age dummies (t-1) and birth cohort were included as covariates but the coefficients are not displayed. All coeficientes are significant at the 0.01 level. 
The positive association is stronger for men. The main difference between men and women occurs above the median income. Men at the ninth and tenth decile have 51 and 74 percent higher risk of childbearing, respectively, compared with the fifth decile, while the corresponding numbers for women in the same categories are 11 and 22 (Table 4, Column I). However, differences go in the other direction at the lower end of the distribution even though they are not as big. The reduced risk of childbearing in the first decile, compared to the reference category, is 58 percent for women and 46 percent for men. Tertiary education is associated with an increased risk of having the first child for both men and women. The u-shape pattern we observe for women, where the secondary level is associated with the lowest risk, resembles the results given by Santow and Bracher (2001). Sensitivity tests in which enrollment was not included gave very similar results for men and women (not shown).

Enrollment in education clearly has a different impact for men and women (in line with previous studies). The models show that women who have not yet finished their education are less likely to enter parenthood and the penalty is more than four times bigger for women than for men (32 and 7 percent respectively).

In addition to the strong impact of personal income, the economic environment also affects the risk of parenthood. Years of high demand for work (top quintile by number of vacancies) increases the risk of childbearing the following year by 40 percent compared with years with medium demand (third quintile) and it is reduced by 6-8 percent in years with low demand (lowest quintile).

Figure 1 presents the net effect by period when interaction terms between income and time periods are added to the previous model. We can see that changes over time are mainly driven by what happens above the median income. The differential risk of those at the lower deciles compared to the median income remains rather constant across time. On the other hand, the difference between the top deciles and the median rockets after 1990 .

Changes over time show a clear gendered pattern. Women and men were always less likely to enter parenthood if their income was below the median. Changes over time in this regard are rather small. However, before 1990, women earning above the median were not at a higher risk of childbearing. From the 1990s onward, the behavior of women became more similar to that of men and a clearly linear association between income and the transition to parenthood emerged. The association between income and the transition to parenthood for men is linear in all periods but it becomes much stronger in the latter decades.

Interaction terms between income deciles and demand for work (in quintiles) are displayed in Figure 2. The results show that income tends to be a more relevant factor when the demand for work is low. Overall fertility is reduced in Sweden during recessions, but it looks like there are important variations connected with income. When the economic outlook seems grim, being at the upper end of the income distribution makes a bigger difference in terms of childbearing risk. This is likely because individuals at 
Figure 1: Relative risk of entering parenthood by income decile: net effects by period
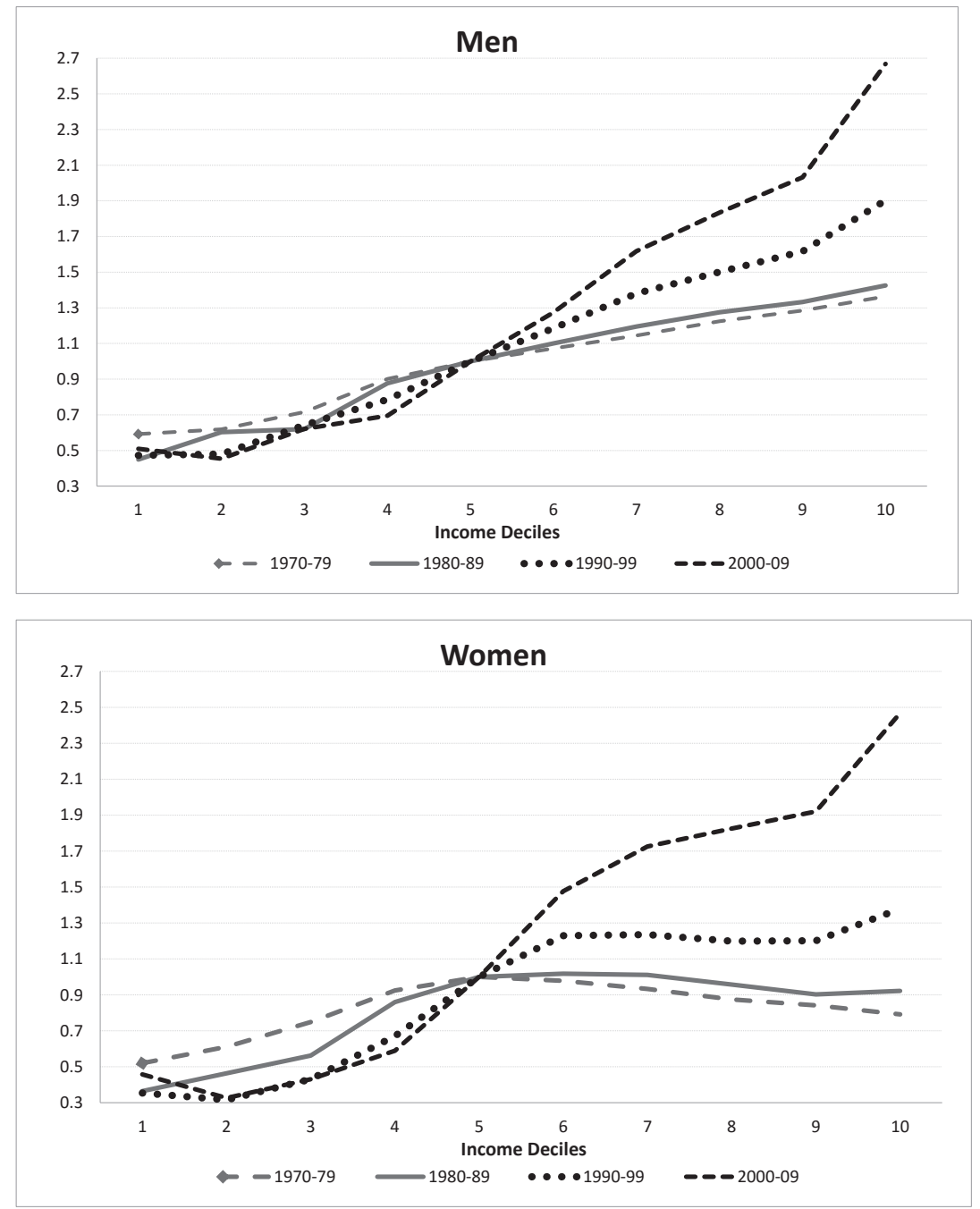

Notes: Net effects were obtained by multiplying the coefficient on income deciles and interactions terms between income deciles and periods. Education, enrollment, age, and vacancies were included as covariates.

the lower end of the income distribution disproportionately choose to postpone fertility. When the economic context improves, income differentials diminish.

Again, the most interesting feature of Figure 2 is the gender differences. In times of low demand for work, men in the top decile of the income distribution exhibit a relative risk 
Figure 2: Relative risk of entering parenthood by income decile: net effects by demand for work (vacancies)
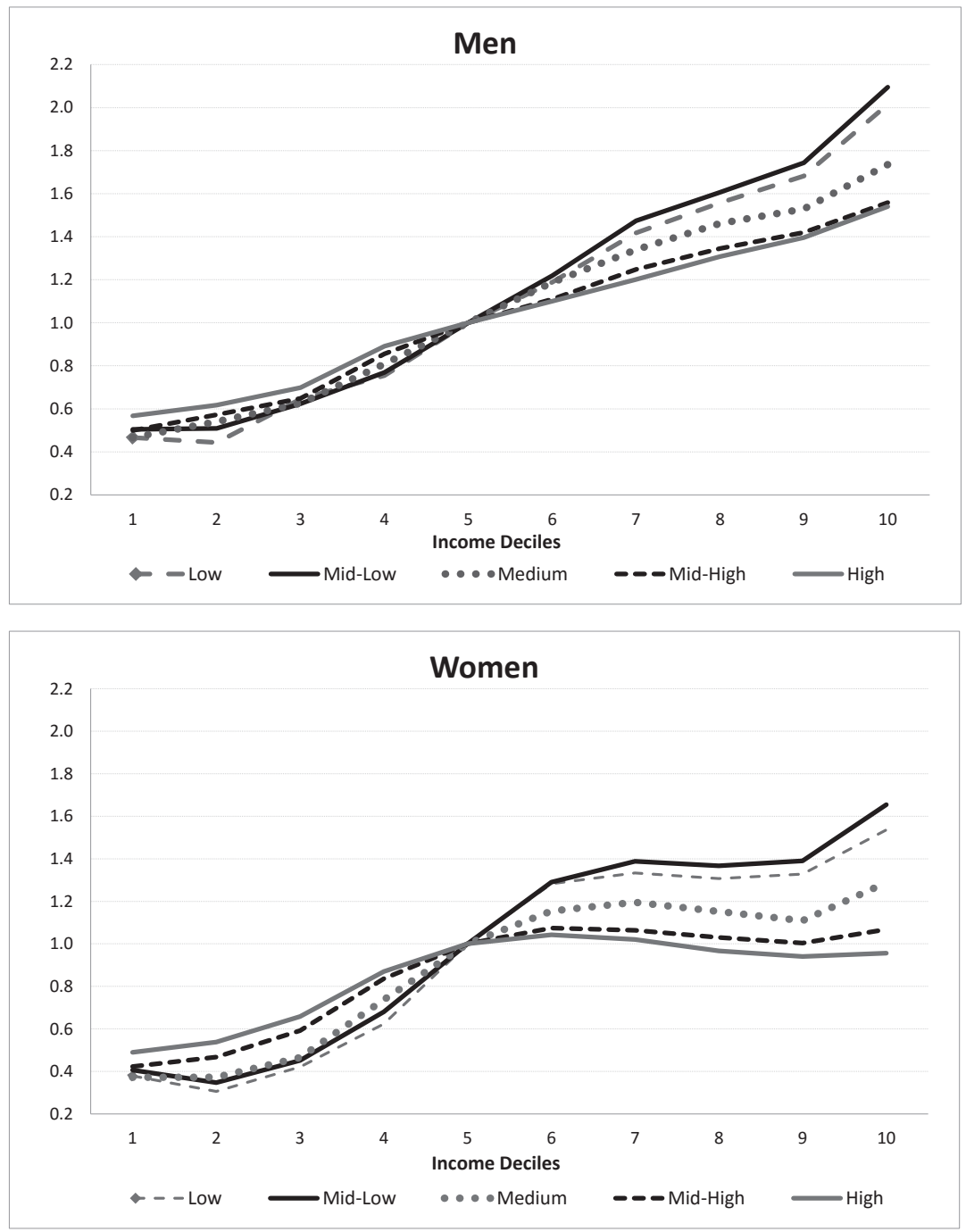

Notes: Net effects were obtained by multiplying the coefficient on income deciles and interactions terms between income deciles and vacancies. Education, enrollment, age, and cohort were included as covariates.

of entering parenthood 100 percent higher than their peers in the reference category. The difference is reduced to fifty percent when demand for work is high. In the case of women, the difference between the top decile and the reference category is fifty percent in bad years but disappears when demand for work is high. 


\section{Discussion}

The first hypothesis about the positive association between income and childbearing is clearly supported by the evidence. In line with previous research in Sweden and in other Nordic countries (Andersson et al., 2001; Vikat 2004), we see that the risk of entering parenthood increases as the relative income rises for both men and women. We can also observe that fertility is pro-cyclical as higher demand for work correlates with higher entry into parenthood.

The positive association between income and entry into parenthood strengthens over time as was predicted in Hypothesis 2. It is also evident that changes were more dramatic for women. Two historical processes play a role in strengthening the association: increasing opportunities to combine work and family (parental leave, childcare services) and decreasing economic security (higher unemployment, rising inequality). The first element is likely to have affected women more than men and therefore the findings are not surprising. The second element probably affected the ability of men to be breadwinners after childbearing, which may induce postponement among men with low incomes, and may also push women to be less reliant on their partners. Even though Sweden is characterized by high participation of women in the labour force, mothers are more likely than fathers to take part-time jobs; this implies that the ability of men to be the main breadwinner after childbearing is still relevant.

It is important to note that the negative association between income and fertility that traditional perspectives predict for women does not appear in any period. An income below the median always reduces the risk of having the first child. Women with high earnings were likely to pay higher opportunity costs for their children in the 1970s, but their risk of entering motherhood was similar to women with medium incomes and higher than women with low-incomes. What has changed over the time covered by this study is that women now seem to have an incentive to have high earnings -and not just average earnings- before entering motherhood. Such an incentive could be interpreted from two perspectives. First, relying on the man to be the main breadwinner may be considered less suitable (for personal motives, increasing aspirations, or changes in the economic context). Second, the ability to retain the gains from a better job may have increased (social policies). These changes become evident after 2000, well after the current parental leave scheme was introduced in the mid-1970s. Nevertheless, this does not mean that social policies are irrelevant to the change in the childbearing attitudes of women. I will suggest that the expansion of childcare throughout the 1980s and 1990s was important to neutralize the opportunity costs associated with higher incomes.

The overall results shown in Table 4, when the models are applied to whole period 1969-2009, also show gender differences. Hypotheses 3 and 4 were formulated as alternatives, but the evidence can be interpreted in a way in which both have some support and are complementary to each other.

As presented in the previous section, women in the top decile of the income distribution have a 22 percent increased risk of having a child the following year compared to 
the reference category, while the difference for men is more than three times greater, a pattern that fits Hypothesis 3 (traditional gender roles). At the other end of the income distribution, however, the size of the effect is greater for women as predicted by Hypothesis 4 (risk reduction and/or independence): the risk of childbearing is reduced 58 percent for women and 46 percent for men at the lower decile.

Low income pushes women to postpone or forgo entry into parenthood even more than men. If women are more likely to take time away from work after childbearing, then their earnings and job position in the years to come are going to be greatly determined by their prior position in the labour market. Meanwhile, most fathers will not interrupt their careers to the same extent and thus, they will have a better chance to improve their stance in the labour market even after the child is born. It is therefore reasonable to conclude that not having a precarious position in the labour market is more important for women than for men. This situation did not change over time.

Earnings above the median increase the risk of childbearing for both men and women but in this case, coefficients are clearly higher for men. This seems to be consistent with traditional gender roles: women are expected to pay higher opportunity costs. Women still have an incentive to set a foothold in the labour market before childbearing, but the incentive is not as strong as it is for men. For women who may take a long break from labour force afterward childbearing and may return to work with reduced hours, there may not be an extra incentive to progress further in the labour market before childbearing. This interpretation is consistent with the changes over time that I have already discussed. If the ability to reduce opportunity costs has increased over time, then the behavior of women above the median income should become more similar to that of men as time passes, this is precisely what happened. Earnings above the median still have a greater impact for men than for women, but the differences have decreased substantially.

Hypothesis 5 predicted that aspirations will be harder to fulfill in times of economic recession and therefore the transition to parenthood should be more selective on income when the demand for work is low. Indeed, that was confirmed by the results shown in Figure 2. For men, the difference between times of high and low demand for work is a matter of quantum. High income increases the risk of childbearing to a greater extent when the context is bad. For women, the change is even more evident. An income above the median does not increase the risk of childbearing when the demand for work is relatively high. A possible explanation is that when the labour market situation is good, women may be more likely to rely on their partners to be the breadwinner and therefore there is less pressure to postpone childbearing until the paycheck gets better. This could be read as additional support for Hypothesis 3. Traditional gender patterns may still play a role in Sweden.

Finally, an important limitation of the data is the lack of information on partnerships before parenthood. The association found between income and childbearing may be the consequence of an underlying association between income and the probability of finding 
a suitable partner. Such interpretation is not new for men. Gary Becker (1991) already theorized that highly productive men would have an edge on the marriage market due to their ability to become good providers. Women traditionally were not expected to become providers so their earning capacity was not considered as much of an asset in the marriage market, even though this may have changed in recent decades. Perhaps income is related to the possibility of interacting with desirable partners and high-income women -or men- have it easier to find the right person to start a family.

The results of this study show a strong association between income and the risk of having the first child. Whether this association occurs due to individual decisions or due to different levels of success in the mating market, it requires further studies and more information on union formation patterns. It is likely that forming a stable union is indeed a mediating factor between income and parenthood. Income signals the ability to support children and therefore it is something that persons look in prospective partners when they intend to form long-term relationships.

\section{Conclusions}

This study brings additional support to the notion that Sweden fits with what has been called the Nordic Fertility Regime. Fertility is pro-cyclical and having a foothold in the labour market is almost a precondition for parenthood. The evidence shows that the positive association between income and the transition to parenthood strengthened over the four decades covered here. For men, that meant business as usual, however, for women that time period represents an important transformation. This provides further support for previous studies such as Dribe and Stanfors (2009), who concluded that, over time, the relationship between work and parenthood became increasingly similar for men and women.

Among the most important conclusions to draw from this study are the importance of including both men and women in fertility studies, because gender differences can shed light on some important aspects of the topic. While changes over time were only incremental for men, women went from a situation in which an income above the median has little impact on the transition to parenthood to a linear relationship between income and the risk of childbearing, quite similar to that of men.

It is very interesting, however, to pinpoint the gender differences. Throughout this study we have seen that receiving an income below the median is always a factor that delays childbearing and the impact is even higher for women than for men. On the other side, how an income above the median relates to the risk of childbearing varies much more depending on individual circumstances. In general, an income above the median has a lower impact on women than on men, but there are two circumstances in which the pattern changes more radically.

When the demand for work is high, an income above the median does not increase the risk of childbearing for women. This is not the case for men in a similar situation 
or even for women when the demand for work is low. This shows an interesting avenue for further research in order to more thoroughly investigate this gender pattern and see whether or not this implies that the income of women is playing some sort of subsidiary role in many households.

\section{Acknowledgements}

This work is part of the project "Towards the modern family. Socioeconomic stratification, family formation and fertility in a historical perspective", funded by the Swedish Research Council and the Crafoord foundation. I am also indebted to Martin Dribe, Anders Nilsson, and Jonas Helgertz for their valuable advice and comments.

\section{References}

Ahn, N and Mira, P. 2002. A Note on the Changing Relationship between Fertility and Female Employment Rates in Developed Countries. Journal of Population Economics 15:667-682.

Andersson, G. 2000. The Impact of Force Participation on Childbearing Behavior: Pro Cyclical Fertility in Sweden during the 1980s and the 1990s. European Journal of Population 16:293-333. Andersson, G and Scott, K. 2007. Childbearing Dynamics of Couples in a Universalistic Welfare State: The Role of Labour Market Status, Country of Origin, and Gender. Demographic Research 17:897-938.

Andersson, G; at al. 2009. Cohort Fertility Patterns in the Nordic Countries. Demographic Research 20:313-352.

Andress, HJ; Golsch, K and Schmidt, AW. 2013. Applied Panel Data Analysis for Economic and Social Surveys. Springer.

Becker, G. 1991. A Treatise on the Family. Harvard University Press, Cambridge.

Bengtsson, N; Holmlund, B and Waldenström, D. 2012. Lifetime Versus Annual Tax Progressivity: Sweden 1968-2009. Forschunginstitut zur Zukunft der Arbeit, Bonn.

Bernhardt, E. 1993. Fertility and Employment. European Sociological Review 9:25-42.

Berninger, I. 2013. Women's Income and Childbearing in Context: First Births in Denmark and Finland. Acta Sociologica 52:97-115.

Billari, F and Kohler, HP. 2004. Patterns of Low and Lowest-Low Fertility in Europe. Population Studies 58:161-176.

Björklund, A and Freeman, R. 1994. Generating Equality and Eliminating Poverty: The Swedish Way. National Bureau of Economic Research, Princeton University Press.

Björklund, A. 2006. Does Family Policy Affect Fertility? Journal of Population Economics 19:3-24.

Boschini, A at al. 2011. Trading Off or Having It All? Completed Fertility and Mid-Career Earnings of Swedish Men and Women. Institute for Market Policy Evaluation, Working Paper 2011:15.

Breusch, T and Gray, E. 2004. New Estimates of Mothers Forgone Earnings Using HILDA Data. Australian Journal of Labour Economics 7:125-150.

Brewster, K and Rindfuss, R. 2000. Fertility and Womens Employment in Industrialized Nations. Annual Reviews 26:271-296.

Budig, M and England, P. 2001. The Wage Penalty for Motherhood. American Sociological Review 66:204-225

Butz, W and Ward, M. 1979. The Emergence of Countercyclical US Fertility. American Economic Review 69:318-328. 
Castles, F. 2003. The World Turned Upside Down: Below Replacement Fertility, Changing Preferences and Family Friendly Public Policy in 21 OECD Countries. Journal of European Social Policy 13:209-227.

Dribe, M and Stanfors, M. 2009. Education, Work and Parenthood: Comparing the Experience of Young Men and Women in Sweden. Journal of Family and Economic Issues 30:32-42.

Duvander, AZ; Lappegård, T and Andersson, G. 2010. Family Policy and Fertility: Fathers and Mothers use of Parental Leave and Continued Childbearing in Norway and Sweden. Journal of European Social Policy 20:45-57.

Easterlin, R. 1976. The Conflict between Aspirations and Resources. Population and Development Review 2:417-425.

Ellingsaeter, AL. 2009. Leave Policy in the Nordic Welfare States: A Recipe for High Employment and High Fertility? Community, Work and Family 12:1-19.

Esping-Andersen, G. 1990. The Three Worlds of Welfare Capitalism. Princeton University Press, Princeton, New Jersey.

Gronau, R. 1977. Leisure, Home Production and Work: the Theory of the Allocation of Time Revisited. The Journal of Political Economy 85:1099-1123.

Happel, SK; Hill, JK; and Low, SA. 1984. An Economic Analysis of the Timing of Childbirth. Population Studies 38: 299-311.

Hoem, B. 2000. Entry into Motherhood in Sweden. Demographic Research 2.

Hoem, J. 1990. Social Policy and Recent Fertility Change in Sweden. Population and Development Review 4:735-748.

Hoem, J; Neyer, G and Andersson, G. 2006. Education and Childlessness. The Relationship between Educational Field, Educational Level, and Childlessness among Swedish Women born in 1955-59. Demographic Research 14:331-380.

Hultåker, O. 1982. Forms of Childcare in Sweden: Experiences and Acceptance. Journal of Comparative Family Studies 13:209-219.

Jalovaara, M and Miettinen, A. 2013. Does his Paycheck also Matter? The Socioeconomic Resources of Co-Residential Partners and Entry into Parenthood in Finland. Demographic Research 28:881-916.

Joshi, H. 1990. The Cash Opportunity costs of Childbearing: An Approach to Estimation Using British Data. Population Studies 44:41-60.

Kögel, T. 2004. Did the Association between Fertility and Female Employment within OECD Countries Really Change its Sign? Journal of Population Economics 17:45-65.

Kohler, HP; Billari, F and Ortega, JA. 2002. The Emergence of Lowest-Low Fertility in Europe during the 1990s. Population and Development Review 28:641-680.

Kravdal, Oystein. 1992. Forgone Labour Participation and Earning due to Childbearing among Norwegian Women. Demography 29:545-563.

Kravdal, Oystein. 1994. The Importance of Economic Activity, Economic Potential and Economic Resources for the Timing of First Births in Norway. Population Studies 48:249-267.

Kravdal, Oystein and Rindfuss, Ronald. 2008. Changing Relationships between Education and Fertility: A Study of Women and Men Born 1940 to 1964. American Sociological Review 73:854-873.

Lappegård, Trude and Ronsen, Marit. 2005. The Multifaceted Impact of Education on Entry into Motherhood. European Journal of Population 21:31-49.

Lappegård, Trude; Ronsen, Marit and Skrede, Kari. 2011. Fatherhood and Fertility. Fathering 9:103120.

Liefbroer, A, and Corijn, M. 1999. Who, What, Where, and When? Specifying the Impact of Educational Attainment and Force Participation on Family Formation. European Journal of Population 15:45-75.

Liefbroer, A. 2005. The Impact of Perceived Costs and Rewards of Childbearing on Entry into Parenthood: Evidence from a Panel Study. European Journal of Population 21:367-391.

Lindbeck, A. 1997. The Swedish Experiment. Journal of Economic Literature 35:1273-1319. 
Lundberg, S and Rose, E. 2000. Parenthood and the Earnings of Married Men and Women. Economics 7:689-710.

Lutz, W; Skirbekk, V and Testa, MR. 2006. The Low Fertility Trap Hypothesis: Forces That May Lead to Further Postponement and Fewer Births in Europe. Vienna Yearbook of Population Research 2006:167-192.

Macunovich, D. 1998. Fertility and the Easterlin Hypothesis: An Assessment of the Literature. Journal of Population Economics 11:1-59.

Matysiak, A and Vignoli, D. 2008. Fertility and Womens Employment: A Metaanalysis. European Journal of Population 24:362-384.

Meyer, A. 2007. Studies on the Swedish Parental Insurance. Lund Economic Studies 140, Lund.

Miller, A. 2011. The Effects of Motherhood Timing on Career Path. Journal of Population Economics 24:1071-1100.

Moss, P and Deven, F. 2006. Leave Policies and Research: A Cross National Overview. Marriage and Family Review 39:255-285.

Neyer, G and Andersson, G. 2008. Consequences of Family Policies on Childbearing Behaviour: Effects or Artifacts? Population and Development Review 34:699-724.

Olsson, S. 1993. Social Policy and Welfare State in Sweden. Lund Studies in Social Welfare, Lund.

Ronsen, M. 2004. Fertility and Public Policies: Evidence from Norway and Finland. Demographic Research 10:143-170.

Rindfuss, R and Brewster, K. 1996. Childrearing and Fertility. Population and Development Review 22:258-289.

Santow, G and Bracher, M. 2001. Deferment of the First Birth and Fluctuating Fertility in Sweden. European Journal of Population 17:343-363.

Schön, L. 2012. An Economic History of Modern Sweden. Routledge, London.

Sobotka, T; Skirbekk, V and Philipov, D. 2011. Economic Recession and Fertility in the Developed World. Population and Development Review 37:267-306.

Stanfors, M. 2003. Education, Labour Force Participation and Changing Family Patterns. A Study of Swedish Women and Socioeconomic Change in Twentieth Century Sweden. Lund Studies in Economic History 22, Lund.

Sundström, M and Duvander, AZ. 2002. Gender Division of Childcare and the Sharing of Parental Leave among New Parents in Sweden. European Sociological Review 18:433-447.

Tesching, K. 2012. Education and Fertility. Stockholm University Demography Unit. Dissertation Series.

Thalberg, S. 2011. Does Money Matter? Childbearing Behavior of Swedish Students in the 1980s and 1990s. Finnish Yearbook of Population Research 46:5-19.

Van Lacker, W and Ghysels, J. 2012. Who Benefits? The Social Distribution of Subsidized Childcare in Sweden and Flanders. Acta Sociologica 55:125-142.

Vikat, A. 2004. Women's Labour Force Attachment and Childbearing in Finland. Demographic Research 3:177-211.

Waldenström, D. 2009. Lifting All Boats? The Evolution of Income and Wealth Inequality over the Path of Development. Lund Studies in Economic History 51, Lund. 